Check for updates

Cite this: Chem. Commun., 2017, 53, 5733

Received 24th March 2017,

Accepted 4th May 2017

DOI: $10.1039 / c 7 c c 02244 a$

rsc.li/chemcomm

\section{Alkynyl sulfoxides as $\alpha$-sulfinyl carbene equivalents: gold-catalysed oxidative cyclopropanation $\uparrow$}

\author{
Matthew J. Barrett, Ghulam F. Khan, Paul W. Davies (D) * and Richard S. Grainger (D)*
}

\begin{abstract}
Alkynyl sulfoxides are shown to act as $\alpha$-sulfinyl metallocarbene synthons under oxidative gold catalysis, enabling reactions that are not available from diazo-precursors. This strategy is exemplified in the synthesis of fused $\alpha$-sulfinyl cyclopropanes.
\end{abstract}

Metallocarbenes underpin a broad range of powerful chemo- and stereoselective transformations in modern organic synthesis. ${ }^{1}$ $\alpha$-Sulfinyl metal carbenes, $\mathbf{1}$, position a readily-elaborated functional group ${ }^{2-5}$ bearing a stereogenic centre at the reactive site (Scheme 1a). ${ }^{6}$ However this attractive proposition has yet to be realised using conventional approaches to metal carbene reactivity. Maguire and co-workers established that $\alpha$-diazo sulfoxides are only isolable when constrained as part of a cyclic system and that they and their resulting $\alpha$-sulfinyl rhodium carbenes undergo rapid Wolff-like rearrangement (Scheme 1b). ${ }^{7}$ Here we demonstrate how the reactivity patterns of $\alpha$-sulfinyl carbenes can be accessed from alkynyl sulfoxides under gold catalysis.

The use of a $\pi$-acid to chemoselectively activate alkynes in the presence of a nucleophilic oxidant provides an attractive route into $\alpha$-oxo metal carbene reactivity patterns without the need to install or handle diazo groups..$^{8-11}$ One intriguing aspect is that some reactions appear to bypass the actual gold carbene $\mathbf{4}$ and proceed directly from the vinyl gold carbenoid intermediate 3 (Scheme 1c). ${ }^{12}$ We hypothesised that broader applications of $\alpha$-sulfinyl metal carbene chemistry might therefore be accessible if $\alpha$-sulfinyl vinyl gold carbenoid 7 could be accessed from alkynyl sulfoxide $\mathbf{6}$, quenched prior to expulsion of the nucleofuge, and proved less vulnerable to rearrangement than the corresponding metal carbene. This approach presents an interesting challenge as sulfoxides are effective nucleophiles and oxygen-transfer agents in the presence of alkyne-gold complexes ${ }^{13}$ or metal carbenes. ${ }^{14}$ For successful application

School of Chemistry, University of Birmingham, Edgbaston, Birmingham B15 2TT, UK.E-mail: p.w.davies@bham.ac.uk,r.s.grainger@bham.ac.uk

$\dagger$ Electronic supplementary information (ESI) available: Experimental procedures and analytical data for new compounds. ${ }^{1} \mathrm{H}$ and ${ }^{13} \mathrm{C}$ NMR spectra. Structural determination and additional catalysis results. CCDC 1528851. For ESI and crystallographic data in CIF or other electronic format see DOI: 10.1039/c7cc02244a (a) $\alpha$-Sulfinyl metal carbenes: a desirable but unrealised reactivity profile

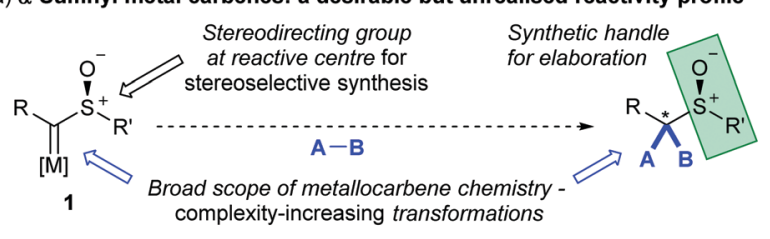

(b) Diazo precursors to rhodium carbenes (Maguire)

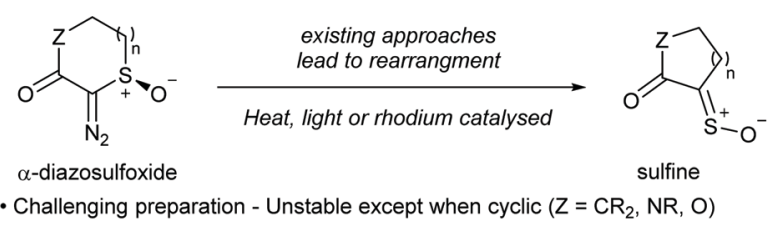

(c) The alkyne oxidation strategy to $\alpha$-oxo metal carbenes

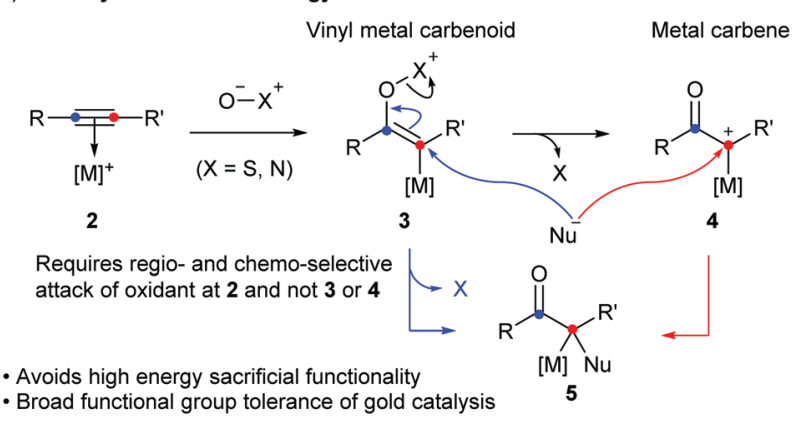

(d) Unlocking the potential of $\alpha$-sulfinyl carbenoids (this work)

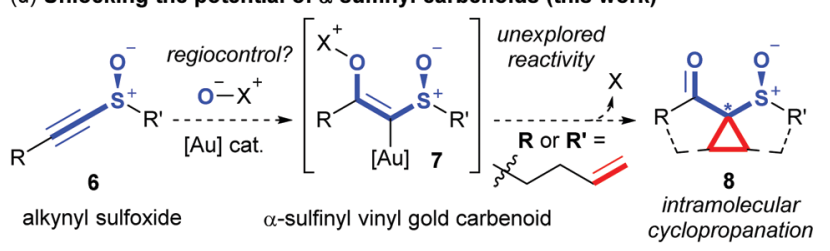

- Readily prepared precursors - Sulfinyl group must direct and not react

Scheme 1 Approaches to access $\alpha$-sulfinyl metal carbene type reactivity.

of alkynyl sulfoxide 6 as an $\alpha$-sulfinyl carbene equivalent, effective $\pi$-activation and regioselective oxidation is required, but 6 and 8 must not act as nucleophilic oxidants. ${ }^{15}$ 
We tested this hypothesis in the oxidative cyclopropanation reaction of readily accessible ene-alkynyl sulfoxides. $\ddagger$ A reaction survey with 9a identified that the desired cyclopropane-fused thiolane $S$-oxide was formed as an approximately $6: 1$ mixture of diastereomers 10a and 10b using 3,5-dichloropyridine- $N$ oxide (11) as stoichiometric oxidant in the presence of various cationic $\mathrm{Au}(\mathrm{I})$ catalysts. Phosphite, N-heterocyclic carbene and bulky phosphine ligands all proved effective on the gold, with SPhosAuNTf $_{2}$ giving highest yield (Table 1, entries 1-5). Dioxane proved superior to other solvents (entries 5-9) while 11 was more effective than other commonly used pyridine- $N$-oxide derivatives 12 and 13 (entries 10-13). ${ }^{16}$ Changing the temperature had little effect on dr, though conversion stalled at much lower temperatures: at $80{ }^{\circ} \mathrm{C}$ the catalyst loading could be halved with little effect, though dropping further was detrimental to conversion of 9a (entry 10). Increasing oxidant loading saw lower yields, likely due to over-oxidation pathways (entry 11).

A range of ene-alkynyl sulfoxides $\mathbf{9 a - v}$ were prepared to explore the effect of the alkyne substituent on the reaction (Table 2). Primary, secondary and tertiary alkyl substituents were all accommodated with good conversions at $50{ }^{\circ} \mathrm{C}$ (entries 1-6). Notably, cyclopropyl-substituted alkyne 3q gave the same yield and d.r. at room temperature (entry 6). Aryl substituted alkynes were also more reactive, proceeding at room temperature, although higher yields were obtained under the standard conditions (entries 7-20, see ESI $\dagger$ for reactions at room temperature).

Table 1 Survey of reaction conditions

\begin{tabular}{|c|c|c|c|c|c|}
\hline \multirow[b]{2}{*}{ Entry } & \multirow{2}{*}{$\frac{9 a}{\text { Ligand }}$} & \multirow[b]{2}{*}{ Solvent } & \multicolumn{2}{|c|}{ 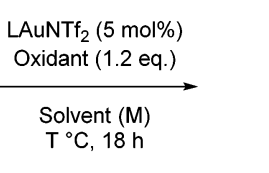 } & \multirow{2}{*}{ 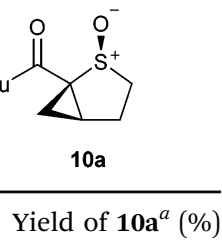 } \\
\hline & & & $T\left({ }^{\circ} \mathrm{C}\right)$ & Oxidant & \\
\hline 1 & L1 & Dioxane & 65 & 11 & 42 \\
\hline 2 & $\mathrm{~L} 2$ & Dioxane & 65 & 11 & 45 \\
\hline 3 & L3 & Dioxane & 65 & 11 & 47 \\
\hline 4 & L4 & Dioxane & 65 & 11 & 59 \\
\hline 5 & L5 & Dioxane & 65 & 11 & 66 \\
\hline 6 & L5 & 1,2-DCE & 60 & 11 & 45 \\
\hline 7 & L5 & THF & 60 & 11 & 37 \\
\hline 8 & L5 & $\mathrm{CH}_{2} \mathrm{Cl}_{2}$ & $\mathrm{rt}$ & 11 & 26 \\
\hline 9 & L5 & Toluene & 60 & 11 & 39 \\
\hline 10 & L5 & Dioxane & 80 & 11 & $69^{b, c}$ \\
\hline 11 & L5 & Dioxane & 80 & 11 (2.0 eq.) & 54 \\
\hline 12 & L5 & Dioxane & 80 & 12 & 63 \\
\hline 13 & L5 & Dioxane & 80 & 13 & 59 \\
\hline
\end{tabular}

${ }^{a}$ Reactions performed on a $0.1 \mathrm{mmol}$ scale; yields of the major diastereomer 10a determined by ${ }^{1} \mathrm{H}$ NMR analysis of the crude reaction mixture using 1,2,4,5-tetramethylbenzene as an internal reference. Overlap prevented accurate determination of $\mathrm{dr} .{ }^{b} 62 \%$ at $2.5 \mathrm{~mol} \%$ cat. $27 \%$ at $1.0 \mathrm{~mol} \%$ cat. $\mathrm{L} 1=($ tris(2,4-di-tertbutylphenyl)phosphite) . L2 = 1,3-bis(2,6-diisopropylphenyl-imidazol-2-ylidene). L3 = 2-dicyclohexylphosphino-2' $4^{\prime}, 6^{\prime}$-triisopropylbiphenyl. L4 = 2-ditertbutylphosphinobiphenyl. L5 = 2-dicyclohexylphosphino-2',6'-dimethoxybiphenyl (SPhos). ${ }^{c}$ Higher concentrations afforded lower yields ( $42 \% 10$ a at $0.2 \mathrm{M}$ ).<smiles>[O-][n+]1cc(Cl)cc(Cl)c1</smiles><smiles>[O-][n+]1cccc(Br)c1</smiles><smiles>Cc1cccc2ccc[n+]([O-])c12</smiles>

In these cases the d.r. was approximately $8: 1$ as determined by ${ }^{1} \mathrm{H}$ NMR analysis of the reaction mixture before purification. The aromatic substituent can be either electron-rich or -poor and will accommodate a variety of functionality across all positions. The tolerance of this chemistry is highlighted by the ready inclusion of a 3-bromothiophen-2-yl moiety (entry 20). Furthermore, the reactions of diene-alkynyl sulfoxides $9 \mathbf{u} / \mathbf{v}$ proceeded smoothly to the desired sulfur heterocycles despite the possibility of competing cycloisomerisation prior to oxidation across one or both of the two 1,6-enyne motifs embedded in the substrates (entries 21 and 22). ${ }^{17}$

The relative stereochemistry of the major diastereomers $\mathbf{1 0}$ and minor diastereomers $\mathbf{1 0}^{\prime}$ were assigned using characteristic chemical shifts in the ${ }^{1} \mathrm{H}$ NMR spectra (see ESI $\dagger$ ).

In addition a crystal structure was obtained for major diastereomer 10g (Fig. 1),§ confirming the NMR analysis that the sulfoxide oxygen and cyclopropyl methylene are on the same side of the thiolane ring.

The reaction of $\mathbf{9 q}$, bearing an ortho-isopropyl substituent, saw formation of a side-product alongside 10q (Table 2, entry 17) although this was not isolated in sufficient quantity or purity to

Table 2 Substrate scope

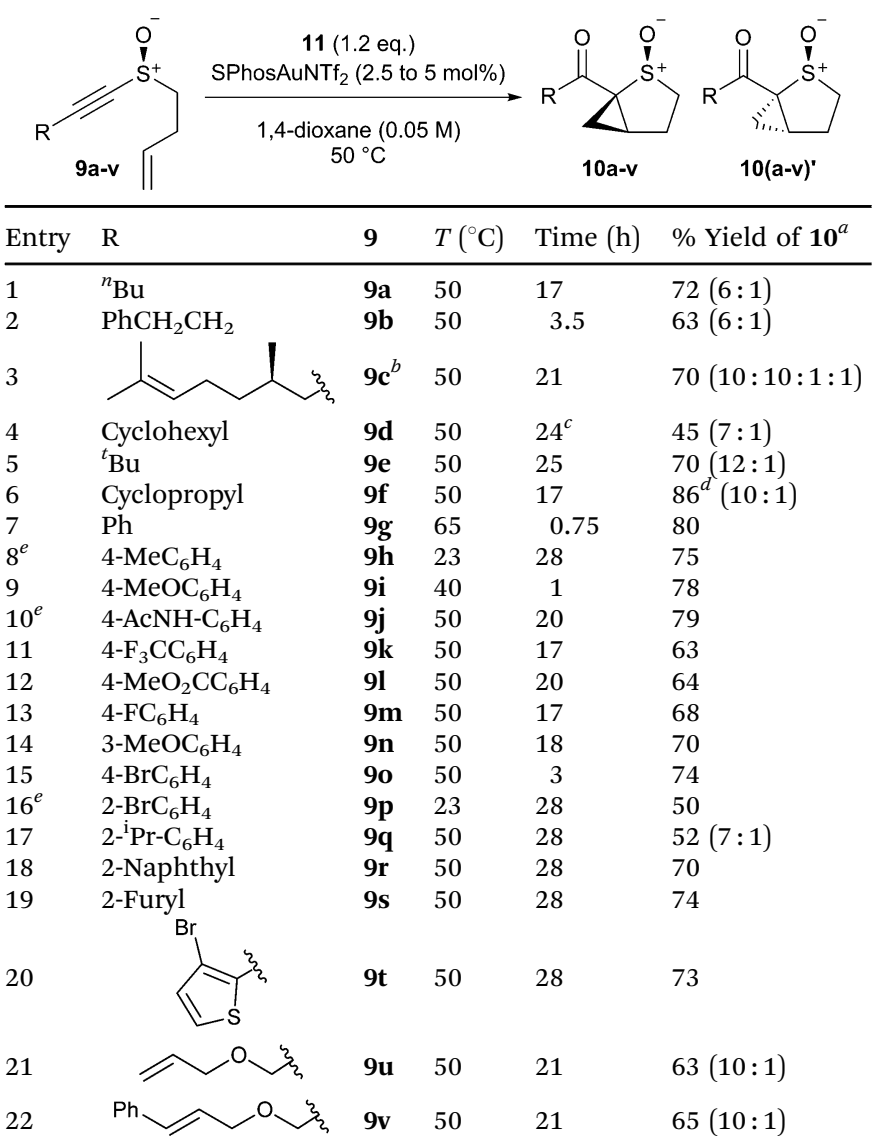

${ }^{a}$ Isolated yields after purification by column chromatography. The yields refer to a single diastereomer apart from when diastereomeric ratios are given. ${ }^{b}$ 9c is a 1:1 mixture of diastereomers. ${ }^{c}$ Incomplete conversion. ${ }^{d}$ The same yield and d.r. were obtained at room temperature. ${ }^{e} 2.5 \mathrm{~mol} \%$ SPhosAuNTf $_{2}$. 


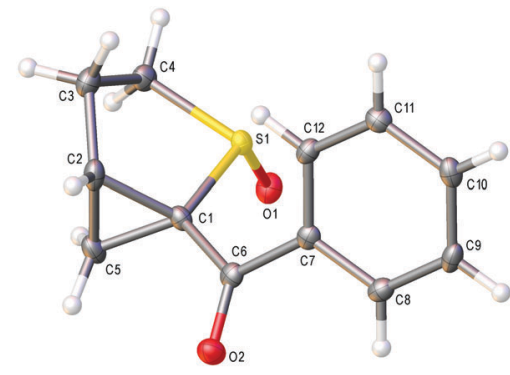

Fig. 1 X-ray crystal structure of major diastereomer $10 \mathrm{~g}$

allow full characterisation. We hypothesised that 1,5-hydride transfer from the benzylic position may be competing with cyclopropanation. ${ }^{18}$ To test this hypothesis we prepared the methylsulfoxide $\mathbf{1 2}$ where cyclopropanation is not possible. The formation of stilbene $\mathbf{1 3}$ under the standard reaction conditions is indeed consistent with 1,5-hydride transfer onto a vinyl gold carbenoid ( $c f .7)$ followed by elimination of a proton and protodeauration (Scheme 2). Key resonances in $\mathbf{1 3}$ also correlate to those in the side-product from $\mathbf{9 q}$.

The feasibility of using a disubstituted alkene in the cyclopropanation was then explored using styrene 14 (Scheme 3). Under the standard reaction conditions the more heavily substituted cyclopropane 15 was indeed formed, ${ }^{19}$ alongside hydroxylated ringopened product 16. Formation of $\mathbf{1 6}$ is consistent with the cationic character of a gold carbenoid extending through the alkene and enabling a hydrative cyclisation in the presence of adventitious water. ${ }^{20}$

A preliminary investigation shows that using alkynyl sulfoxides as $\alpha$-sulfinyl carbene equivalents is not limited to sulfur heterocycle formation. Under unoptimised conditions, which saw incomplete conversion, 1,5-enyne $\mathbf{1 7}$ gave fused carbocyclic ring system 18 as a 1.6:1 mixture of diastereomers (Scheme 4).

In conclusion, the synthetic limitations that have prevented access to desirable aspects of $\alpha$-sulfinyl metallocarbene reactivity can be bypassed by an oxidative gold catalysis strategy using

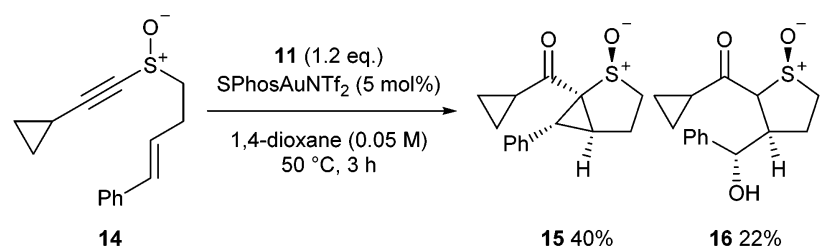

Scheme 3 Use of 1,2-disubstituted alkene in oxidative cyclopropanation.

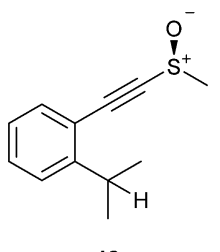

12

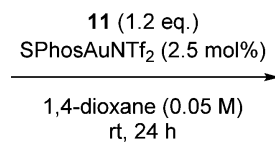

$22 \%(40 \%$ recovered 12$)$

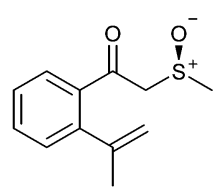

13
Scheme 2 An alternative reaction pathway consistent with 1,5-hydride transfer.

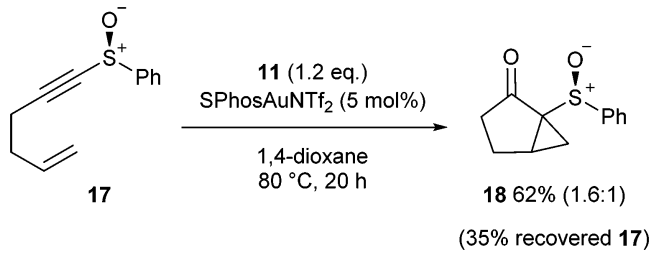

Scheme 4 Synthesis of an $\alpha$-sulfinyl cyclopropyl-fused cyclopentanone.

readily accessed alkynyl sulfoxides. For the first time $\alpha$-sulfinyl carbene-like activity is demonstrated through intramolecular cyclopropanation reactions, affording ring-fused cyclopropanes containing $\alpha$-sulfinylcarbonyl motifs. ${ }^{21}$ Future work will address the use of this approach in the wider context of carbene reactivity and explore the opportunities arising from the use of enantiopure sulfoxides. ${ }^{22}$

The authors acknowledge support from the Centre for Chemical and Materials Analysis in the School of Chemistry at University of Birmingham (UoB) and thank Dr Louise Male (UoB) for X-ray crystallography. We thank the UoB for a studentship (MJB).

\section{Notes and references}

$\ddagger$ All sulfoxides were prepared in the racemic series.

$\S$ Crystal structure determination of 10g: crystal data for $\mathrm{C}_{12} \mathrm{H}_{12} \mathrm{O}_{2} \mathrm{~S}$ $\left(M=220.28 \mathrm{~g} \mathrm{~mol}^{-1}\right)$ : triclinic, space group $P \overline{1}$ (no. 2), $a=6.2782(3) \AA$, $b=7.1917(3) \AA, c=12.4920(6) \AA, \alpha=86.275(4)^{\circ}, \beta=75.966(4)^{\circ}$, $\gamma=66.086(4)^{\circ}, V=499.87(4) \AA^{3}, Z=2, T=100.01(11) \mathrm{K}, \mu(\mathrm{CuK} \alpha)=$ $2.667 \mathrm{~mm}^{-1}, D_{\text {calc }}=1.463 \mathrm{~g} \mathrm{~cm}^{-3}, 7653$ reflections measured $\left(7.3^{\circ} \leq 2 \Theta \leq\right.$ $\left.144.236^{\circ}\right), 1939$ unique $\left(R_{\text {int }}=0.0218, R_{\text {sigma }}=0.0170\right)$ which were used in all calculations. The final $R_{1}$ was $0.0390(I>2 \sigma(I))$ and $\mathrm{w} R_{2}$ was 0.0963 (all data). The CIF for the crystal structure of $10 \mathrm{~g}$ has been deposited with the CCDC and have been given the deposition number CCDC 1528851.

1 Carbene Chemistry, ed. G. Bertrand, Fontis Media, Lausanne, Switzerland, 2002.

2 For a review of the Pummerer reaction: L. H. S. Smith, S. C. Coote, H. F. Sneddon and D. J. Procter, Angew. Chem., Int. Ed., 2010, 49, 5832-5844.

3 For reviews of elimination reactions of sulfoxides, see: (a) A. L. Schwan, ChemCatChem, 2015, 7, 226-227; (b) M. C. Aversa, A. Barattucci, P. Bonaccorsi and P. Giannetto, Curr. Org. Chem., 2007, 11, 1034-1052. For prior work from one of us, see; (c) S. T. Bedford, R. S. Grainger, J. W. Steed and P. Tisselli, Org. Biomol. Chem., 2005, 3, 404-406; (d) R. S. Grainger, P. Tisselli and J. W. Steed, Org. Biomol. Chem., 2004, 2, 151-153.

4 For recent representative examples of metal-sulfoxide exchange, see: (a) W. M. Dean, M. Šiaučiulis, T. E. Storr, W. Lewis and R. A. Stockman, Angew. Chem., Int. Ed., 2016, 55, 10013-10016; (b) P. J. Rayner, P. O'Brien and R. A. J. Horan, J. Am. Chem. Soc., 2013, 135, 8071-8077; (c) M. Hughes, T. Boultwood, G. Zeppetelli and J. A. Bull, J. Org. Chem., 2013, 78, 844-854.

5 For a recent review of sulfoxide-directed $\mathrm{C}-\mathrm{H}$ functionalization, see: A. P. Pulis and D. J. Procter, Angew. Chem., Int. Ed., 2016, 55, 9842-9860.

6 For reviews on the application of enantiopure sulfoxides, see: (a) S. Otocka, M. Kwiatkowska, L. Madalińska and P. Kiełbasiński, Chem. Rev., 2017, 117, 4147-4181; (b) M. C. Carreño, G. HernándezTorres, M. Ribagorda and A. Urbano, Chem. Commun., 2009, 6129-6144.

7 (a) P. G. McCaw, N. M. Buckley, K. S. Eccles, S. E. Lawrence, A. R. Maguire and S. G. Collins, J. Org. Chem., 2017, 82, 3666-3679; (b) O. C. M. O'Sullivan, S. G. Collins, A. R. Maguire and G. Bucher, Eur. J. Org. Chem., 2014, 2297-2304; (c) S. G. Collins, O. C. M. O'Sullivan, P. G. Kelleher and A. R. Maguire, Org. Biomol. Chem., 2013, 11, 1706-1725; (d) O. C. M. O'Sullivan, S. G. Collins and 
A. R. Maguire, Synlett, 2008, 659-662; (e) O. C. M. O'Sullivan, S. G. Collins, A. R. Maguire, M. Böhm and W. Sander, Eur. J. Org. Chem., 2006, 2918-2924; $(f)$ A. R. Maguire, S. G. Collins and A. Ford, ARKIVOC, 2003, 7, 96-109; $(g)$ W. Sander, A. Strehl, A. R. Maguire, S. Collins and P. G. Kelleher, Eur. J. Org. Chem., 2000, 3329-3335; (h) A. R. Maguire, P. G. Kelleher and S. E. Lawrence, Tetrahedron Lett., 1998, 39, 3849-3852; (i) A. R. Maguire, P. G. Kelleher, G. Ferguson and J. F. Gallagher, Tetrahedron Lett., 1998, 39, 2819-2822.

8 For reviews, see: (a) Z. Zheng, Z. Wang, Y. Wang and L. Zhang, Chem. Soc. Rev., 2016, 45, 4448-4458; (b) H.-S. Yeom and S. Shin, Acc. Chem. Res., 2014, 47, 966-977.

9 For examples in oxidative cyclopropanation, see: $(a) \mathrm{H}$. Chen and L. Zhang, Angew. Chem., Int. Ed., 2015, 54, 11775-11779; (b) K. Ji, Z. Zheng, Z. Wang and L. Zhang, Angew. Chem., Int. Ed., 2015, 54, 1245-1249; (c) H.-S. Yeom and S. Shin, Org. Biomol. Chem., 2013, 11, 1089-1092; (d) A. Homs, M. E. Muratore and A. M. Echavarren, Org. Lett., 2015, 17, 461-463; (e) D. Qian, H. Hu, F. Liu, B. Tang, W. Ye, Y. Wang and J. Zhang, Angew. Chem., Int. Ed., 2014, 53, 13751-13755; $(f)$ K.-B. Wang, R.-Q. Ran, S.-D. Xiu and C.-Y. Li, Org. Lett., 2013, 15, 2374-2377; $(g)$ D. Vasu, H.-H. Hung, S. Bhunia, S. A. Gawade, A. Das and R.-S. Liu, Angew. Chem., Int. Ed., 2011, 50, 6911-6914; (h) D. Qian and J. Zhang, Chem. Commun., 2011, 47, 11152-11154 and references therein.

10 For prior work in this area from one of us, see: $(a)$ M. Dos Santos and P. W. Davies, Chem. Commun., 2014, 50, 6001-6004; (b) P. W. Davies, A. Cremonesi and N. Martin, Chem. Commun., 2011, 47, 379-381; (c) P. W. Davies, Pure Appl. Chem., 2010, 82, 1537-1544; (d) P. W. Davies and S. J. C. Albrecht, Angew. Chem., Int. Ed., 2009, 48, 8372-8375.

11 Review of alkyne $\pi$-acid activations: A. Fürstner and P. W. Davies, Angew. Chem., Int. Ed., 2007, 46, 3410.

12 For examples, see: (a) Ref. 10a; (b) S. Bhunia, S. Ghorpade, D. B. Huple and R.-S. Liu, Angew. Chem., Int. Ed., 2012, 51, 2939-2942.

13 Recent examples $(a)$ T. Matsuda, Y. Nishida, K. Yamanaka and Y. Sakurai, Tetrahedron, 2015, 71, 869-874; (b) M. J. Barrett, P. W. Davies and R. S. Grainger, Org. Biomol. Chem., 2015, 13, 8676-8686; (c) H.-S. Yeom and S. Shin, Org. Biomol. Chem., 2013, 11, 1089-1092; (d) B. Lu, Y. Li, Y. Wang, D. H. Aue, Y. Luo and L. Zhang, J. Am. Chem. Soc., 2013, 135, 8512-8524 and references therein.
14 See ref. 13d and C. A. Witham, P. Mauleon, N. D. Shapiro, B. D. Sherry and F. D. Toste, J. Am. Chem. Soc., 2007, 129, 5838-5839.

15 Alkynyl sulfoxides have been scarcely employed in gold catalysis. For a single example, see G. Zhang and L. Zhang, J. Am. Chem. Soc., 2008, 130, 12598-12599.

16 (a) D. B. Huple, S. Ghorpade and R.-S. Liu, Chem. - Eur. J., 2013, 19, 12965-12969; (b) R. Liu, G. N. Winston-McPherson, Z.-Y. Yang, X. Zhou, W. Song, I. A. Guzei, X. Xu and W. Tang, J. Am. Chem. Soc., 2013, 135, 8201-8204.

17 For a review, see: R. Dorel and A. M. Echavarren, J. Org. Chem., 2015, 80, 7321-7332.

18 In keeping with the oxidative cyclisation of $o$-benzylalkynes, where $\mathrm{C}-\mathrm{C}$ bond formation precedes the elimination observed here, see ref. $12 b$.

19 The methylene protons on the non-fused cyclopropane in $\mathbf{1 5}$ are desymmetrised to 4 distinct resonances, consistent with an interaction with the superimposed phenyl group in an exo position and retention of starting alkene geometry.

20 For example of alkoxycyclisation of enynes in the presence of water C. Nieto-Oberhuber, M. P. Muñoz, S. López, E. Jiménez-Núñez, C. Nevado, E. Herrero-Gómez, M. Raducan and A. M. Echavarren, Chem. - Eur. J., 2006, 12, 1677-1693.

21 All the reaction outcomes are consistent with the sequence of sulfinyldirected oxidation followed by cyclopropanation. For instance, an inverted order of steps would be expected to give rise to vinylcyclopropanes through fast 1,2-CH insertion from alkylalkynes.

22 Although not the focus of this report, analogous cyclopropane-fused sulfolanes can be prepared under the reported reaction conditions starting from the alkynyl sulfone equivalent.

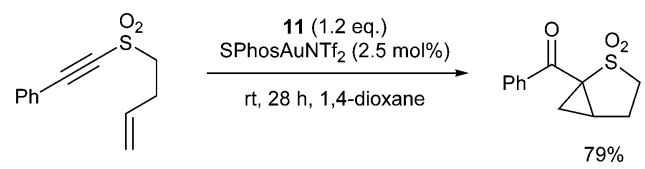

For examples of gold-catalysed oxidative transformations of alkynyl sulfones see: L. Cui, G. Zhang, Y. Peng and L. Zhang, Org. Lett., 2009, 11, 1225-1228 and ref. $9 b$. 